\title{
Characterisation and Kinetic Studies on Activated Carbon Derived from Rubber Seed Shell for the Removal of Methylene Blue in Aqueous Solutions
}

\author{
Nur Fatin Silmi Mohd Azani, ${ }^{1}$ Caryn Tan Hui Chuin, ${ }^{1}$ Nor Salmi Abdullah, ${ }^{2}$ \\ Syazrin Syima Sharifuddin ${ }^{2}$ and M. Hazwan Hussin ${ }^{1 *}$ \\ ${ }^{1}$ Materials Technology Research Group (MaTReC), School of Chemical Sciences, \\ Universiti Sains Malaysia, 11800 USM Pulau Pinang, Malaysia \\ ${ }^{2}$ National Hydraulic Research Institute of Malaysia (NAHRIM), Lot 5377, Jalan Putra \\ Permai, 43300 Seri Kembangan, Selangor, Malaysia \\ *Corresponding author:mhh@usm.my
}

Published online: 25 August 2019

To cite this article: Mohd. Azani, N. F. S. et al. (2019). Characterisation and kinetic studies on activated carbon derived from rubber seed shell for the removal of methylene blue in aqueous solutions. J. Phys. Sci., 30(2), 1-20, https://doi.org/10.21315/jps2019.30.2.1

To link to this article: https://doi.org/10.21315/jps2019.30.2.1

\begin{abstract}
The aim of this research is to investigate and identify the absorption capacity of activated carbon derived from a rubber seed shell (RSS). An RSS was prepared through the conduction of a chemical activation process primarily using potassium hydroxide at a ratio of 1:1 followed by carbonisation at $400^{\circ} \mathrm{C}$ with $N_{2}$ under a steady flow rate of

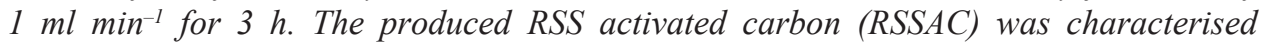
using Fourier transform infrared (FTIR) spectroscopy, scanning electron microscopyenergy dispersive X-ray (SEM-EDX) spectroscopy, Brunauer-Emmet-Teller (BET) analysis and thermogravimetric analysis (TGA). The SEM image obtained revealed the presence of a highly porous RSSAC surface, with an average pore diameter of $3.35 \mathrm{~nm}$, indicating a mesoporous structure. EDX analysis depicted that $C$ and $K$ were major elements found in RSSAC with a compound percentage of $99.73 \%$ and $0.27 \%$, respectively. Batch adsorption studies were conducted to investigate the adsorption properties of RSSAC towards the removal of methylene blue $(M B)$ dye. The optimum dosage of RSSAC was determined to be $5.0 \mathrm{~g}$ per $100 \mathrm{ml}$. Effect of contact time revealed that the highest percentage removal of $M B(99.62 \%)$ by $R S S A C$ was obtained at a concentration of $100 \mathrm{mg} \mathrm{l}^{-1}$ during a time period of $1 \mathrm{~h}$. In comparison, the effect of $\mathrm{pH}$ study affirmed that RSSAC achieved an average removal of $99 \%$ of $M B$ in both acidic and basic media at $100 \mathrm{mg} \mathrm{l}^{-1}$. Kinetic studies revealed that the adsorption process abides by the pseudosecond-order kinetic model. Based on the findings by utilising multiple approaches
\end{abstract}


as mentioned, it can be proposed that RSSAC is a viable alternative to act as a green alternative adsorbent.

Keywords: Rubber seed shell, activated carbon, adsorbent, chemical activation, MB dye

\section{INTRODUCTION}

Water pollution has become one of the major environmental issues which has evidently hindered development progression and efforts toward sustainability of the economic and societal landscape worldwide. It also poses adverse effects on broader biological entities especially the aquatic species. ${ }^{1,2}$ An exemplary scenario would be the rapid growth of textile industries which generate undesirable amounts of dye pollutants which are dumped irresponsibility as well as illegally into clean water resources. Wastewater produced by these textile industries contains a substantial amount of contaminants including acidic and/or caustic-dissolved solids. Most of these dyes are toxic in nature with potential carcinogenic and genotoxic effects. ${ }^{2,3}$ These contaminants can cause severe health-related problems to human beings as well as aquatic life. Therefore, a fast, convenient and efficient method for the removal of dyes from wastewater is highly necessary in treating contaminated water to reduce water pollution.

Various methods have been discovered in relation to dye effluent treatment such as adsorption, coagulation, precipitation, filtration, ozone treatment, chemical oxidation, photocatalytic process, biological treatment and ionising radiation degradation. ${ }^{4}$ Among these treatment methods, adsorption technique utilises a simple application which has proven to be a promising and feasible alternative for wastewater treatment. ${ }^{5}$ A recent research carried out by Borhan et al. reported that the adsorption process with the usage of activated carbon yielded satisfactory adsorptive ability. ${ }^{6}$

Activated carbon is considered as a versatile adsorbent that has been widely used in diverse applications such as in catalytic processes, removal of industrial pollutants, separation and purification of liquid and gaseous currents as well as in biomedical applications. ${ }^{7}$ The demand from industries for a low-cost operational approach for wastewater treatment has encouraged researchers to synthesise low cost and highly efficient adsorbents. Hence, numerous studies have been conducted to identify cost-effective activated carbons derived from lignocellulosic agricultural by-products namely walnut wood, coconut shell and oil palm ash as effective and cheap substitution for the removal of dyes in wastewater. ${ }^{2,7-9}$ Lignocellulosic biomass is known as an economic and eco-friendly material due to their abundant availability, renewability and cost effectiveness which can be used as one of the 
most viable precursors to produce activated carbon. The high content of cellulose, lignin and other polar functional groups of lignin such as alcohols, aldehydes, ketones, carboxylic, phenolic and ether groups in lignocellulosic by-products enhance the adsorbent binding ability of aquatic pollutants through different binding systems. ${ }^{10}$

Among agricultural wastes, rubber seed shell (RSS) has been used intensively by previous researchers as activated carbon precursors due to its abundance and low cost for the removal of heavy metals and dyes from wastewater. ${ }^{10}$ Based on a statistical report issued by the Malaysian Rubber Board in 2014, approximately 1.2 million metric tons of RSS waste from rubber tree plantations are being produced and the numbers have increased exponentially year by year. ${ }^{6}$ RSS is mainly used as a biofuel and manure and it is sometimes left without proper utilisation on the field, leading to increased solid waste disposal and environmental concerns. ${ }^{11}$ Hence, a proper utilisation of RSS waste is important to reduce agricultural waste as well as converting the waste into a much valuable and beneficial material. Recently, RSS is identified as an effective adsorbent, which possesses the qualities to remove $99 \%$ of metal ions from aqueous solutions and has a potential to be utilised as a promising precursor for the production of activated carbon. ${ }^{5}$

This study is focused on the utilisation of local RSS as an activated carbon precursor, application of different methods on adsorbent washing and the $\mathrm{pH}$ optimisation, which have not been adopted in previous studies. Based on previous research conducted on RSS as a source of activated carbon, most of them were focused on the preparation and characterisation of activated carbon derived from RSS. ${ }^{12,13}$ There are only very few studies which have reported the performance of activated carbon derived from RSS for the removal of methylene blue (MB) dye. However, most of the past works reported only on the effect of contact time and the initial concentration where no comprehensive study has been reported on the optimisation of $\mathrm{pH} \cdot{ }^{14,15}$

Thus, the objectives of this study are to prepare activated carbon from local RSS and characterise RSSAC via complementary analyses such as Fourier transform infrared (FTIR), scanning electron microscopy with energy dispersive X-ray (SEM-EDX), $\mathrm{N}_{2}$ Brunauer-Emmet-Teller (BET) analysis and thermogravimetric analysis (TGA). The physicochemical characteristics of RSSAC and the adsorption performance of RSSAC were studied as well. 


\section{EXPERIMENTAL}

\subsection{Materials}

RSS was collected from Ladang Getah Tonng Aung Sdn. Bhd., Kota Bharu, Kelantan, Malaysia in mid-2017. All the chemicals used were of analytical reagent grade. Hydrochloric acid 37\%, sulphuric acid 95\%-97\%, MB powder of high purity $\left(\mathrm{C}_{16} \mathrm{H}_{18} \mathrm{ClN}_{3} \mathrm{~S}, 319.86 \mathrm{~g} \mathrm{~mol}^{-1}\right)$, potassium hydroxide pellet, $\mathrm{KOH}$ (56.11 $\mathrm{g} \mathrm{mol}^{-1}$ ) and commercial activated carbon were purchased from QRëC, Malaysia. MB of high purity was synthesised by chloroform extraction of impurities from a solution of raw dye in borate buffer at $\mathrm{pH} 9.5-10.0$, followed by acidification of the aqueous solution and isolation of the dye. ${ }^{16}$ Distilled water was used for all experiments. Proximate analysis was conducted according to the TAPPI T203 cm09 and laboratory analytical procedure (LAP) method to determine the composition $(\% \mathrm{w} / \mathrm{w})$ of crushed and dried RSS. The composition ( $\% \mathrm{w} / \mathrm{w})$ of RSS was found to contain a moisture level of $7.33 \pm 2.08 \%$, ash content of $1.66 \pm 0.57 \%$, extractives content of $0.86 \pm 0.50 \%$, cellulose content of $38.60 \pm 5.10 \%, 34.50 \pm 1.10 \%$ of hemicelluloses and $17.10 \pm 0.37 \%$ of Klason lignin.

\subsection{Preparation of RSSAC}

RSS was repeatedly washed to remove any solid impurities and later on sun dried. The dried RSS was then crushed into small fragments using a grinder. Crushed RSS was then stored in an oven at $105^{\circ} \mathrm{C}$ overnight. The preparation of activated carbon from RSS was carried out by altering a method by Joshi et al. with slight modifications. ${ }^{11}$ Washed and dried RSS was impregnated by chemical activation where approximately $20 \mathrm{~g}$ of dried RSS was mixed with $200 \mathrm{ml}$ of freshly prepared concentrated solution of $\mathrm{KOH}$ in a ratio $1: 1$ by weight. The mixture was stirred using a magnetic stirrer at $70^{\circ} \mathrm{C}$ until the excess water evaporated. The mixture was kept aside for $24 \mathrm{~h}$ to ensure reagents were fully absorbed into the raw materials. Then, the mixture was filtered and washed with excess distilled water until the $\mathrm{pH}$ reading of the filtrate achieved a reading within the range of 6.0 to 7.0. It was then dried in the oven at $105^{\circ} \mathrm{C}$ overnight.

For carbonisation, the treated and dried RSS was placed in a steel crucible and carbonised in a tubular electric furnace under a steady flow of $\mathrm{N}_{2}$ gas $\left(1 \mathrm{ml} \mathrm{min}{ }^{-1}\right)$ at $400^{\circ} \mathrm{C}$ for $3 \mathrm{~h}$. RSSAC acquired was cooled at ambient room temperature and washed repeatedly with hot distilled water to remove any excess $\mathrm{KOH}$. The $\mathrm{pH}$ of the filtrate was again measured to ensure its $\mathrm{pH}$ was between the range of 6.0 to 7.0. Washed RSSAC was then dried in an oven overnight at $105^{\circ} \mathrm{C}$. After oven drying, RSSAC was sieved to a desired size of $250 \mu \mathrm{m}$ for further analyses. 


\subsection{Characterisation of RSSAC}

The functional groups of RSSAC were determined by FTIR analysis using a Perkin-Elmer System 2000 spectrometer, United States. The sample was prepared using the $\mathrm{KBr}$ method, by mixing each sample with potassium bromide $(\mathrm{KBr})$ at sample to $\mathrm{KBr}$ ratio of 1:10 (by weight). Spectra was recorded at 20 scans per sample utilising transmittance mode in the range of $4000 \mathrm{~cm}^{-1}$ to $400 \mathrm{~cm}^{-1}$ with a resolution of $4.0 \mathrm{~cm}^{-1}$.

BET surface area, pore volume and pore size based on the adsorption of $\mathrm{N}_{2}$ on to RSSAC were acquired using BET equation and Quantachrome Nova Win2 C 1994-2002, United States.

The morphology of RSSAC was analysed via SEM analysis using FEI Quanta 650, Japan. A small amount of RSSAC powder was dispersed to a carbon stud and placed in the FEI Quanta 650 for SEM analysis. The elemental composition was then analysed using EDX spectroscopy (Oxford instruments, X-max).

TGA analysis of RSSAC was analysed using a thermogravimetric analyser (Perkin-Elmer TGA 7, United States). The sample was heated from $30^{\circ} \mathrm{C}$ to $920^{\circ} \mathrm{C}$ at $10^{\circ} \mathrm{C} \mathrm{min}{ }^{-1}$ and held for $5 \mathrm{~min}$ at the highest temperature, which was $920^{\circ} \mathrm{C}$ before cooling it down to $30^{\circ} \mathrm{C}$ to proceed to the second heating.

$\mathrm{pH}_{\mathrm{pzc}}$ analysis was conducted by adopting a method by Tan et al. utilising $100 \mathrm{ml}$ of distilled water with adjusted $\mathrm{pH}$ in the range of $\mathrm{pH} 2.0-12.0$ with $0.1 \mathrm{M} \mathrm{HCl}$ or $0.1 \mathrm{M} \mathrm{NaOH}$. The initial $\mathrm{pH}$ of each adjusted solution was recorded. ${ }^{17}$ Around $5.0 \mathrm{~g}$ of the adsorbent was added into each adjusted $\mathrm{pH}$ solution and was shaken at $100 \mathrm{rpm}$ for $48 \mathrm{~h}$. After $48 \mathrm{~h}$, each sample was filtered to separate activated carbon from the adjusted $\mathrm{pH}$ solution and final $\mathrm{pH}$ values for each adjusted $\mathrm{pH}$ solution were recorded. $\mathrm{A}$ graph of $\mathrm{pH}_{\text {final }}$ against $\mathrm{pH}_{\text {initial }}$ was plotted to represent the effect of $\mathrm{pH}$ on the removal of $\mathrm{MB}$ dye from aqueous solutions. The intersection of the line where $\mathrm{pH}_{\text {final }}=\mathrm{pH}_{\text {initial }}$ was determined as point of zero charge $\left(\mathrm{pH}_{\mathrm{pzc}}\right){ }^{17}$

\subsection{Batch Adsorption Studies}

Seven different dosages of the adsorbent were used to identify the optimum dosage for the removal of $100 \mathrm{mg} \mathrm{l}^{-1} \mathrm{MB}$, which were $0.01 \mathrm{~g}, 0.05 \mathrm{~g}, 0.1 \mathrm{~g}, 0.5 \mathrm{~g}, 1.0 \mathrm{~g}$, $5.0 \mathrm{~g}$ and $10.0 \mathrm{~g}$. Each flask was filled with different dosages of the adsorbent and $100 \mathrm{ml}$ of $100 \mathrm{mg} \mathrm{l}^{-1} \mathrm{MB}$ was added into each flask. Solutions were shaken at $100 \mathrm{rpm}$ for $24 \mathrm{~h}$ where flasks were covered with aluminium foil to prevent the penetration of light. After $24 \mathrm{~h}$, samples were filtered to separate out activated carbon from each MB solution. Upon filtration, concentrations of MB solutions 
were analysed using a spectrophotometer (Shimadzu UV-2600) based on direct reading.

The percentage removal (\%) of each $100 \mathrm{mg}^{-1} \mathrm{MB}$ solution was calculated using Equation 1:

$$
\operatorname{Removal}(\%)=\frac{\left(\mathrm{C}_{0}-\mathrm{C}_{\mathrm{e}}\right)}{\mathrm{C}_{\mathrm{o}}} \times 100
$$

The extent of $\mathrm{MB}$ solution adsorption at equilibrium, $\mathrm{q}_{\mathrm{e}}\left(\mathrm{mg} \mathrm{g}^{-1}\right)$, was calculated using Equation 2:

$$
\mathrm{q}_{\mathrm{e}}=\frac{\left(\mathrm{C}_{\mathrm{o}}-\mathrm{C}_{\mathrm{e}}\right) \mathrm{V}}{\mathrm{W}}
$$

where $\mathrm{C}_{\mathrm{o}}$ corresponds to the initial concentration $\left(\mathrm{mg}^{-1}\right)$ of $\mathrm{MB}$ solution, and $\mathrm{C}_{\mathrm{e}}$ corresponds to the concentration of $\mathrm{MB}$ at equilibrium $\left(\mathrm{mg}^{-1}\right)$. V is the volume of solution in $\mathrm{L}$ and $\mathrm{W}$ is the weight of the adsorbent or optimum dosage of adsorbent in $\mathrm{g}$.

The $\mathrm{pH}$ of $\mathrm{MB}$ solution was prepared in the range of $\mathrm{pH} 2.0-12.0$ by adding a few drops of $0.1 \mathrm{M} \mathrm{HCl}$ or $0.1 \mathrm{M} \mathrm{NaOH}$. The optimum dosage of the adsorbent used for RSSAC was $5.0 \mathrm{~g}$. Thus, $5.0 \mathrm{~g}$ of the adsorbent was added into each $100 \mathrm{ml}$ of adjusted MB solution at varying $\mathrm{pH}(\mathrm{pH} 2.0-12.0)$ and was shaken at $100 \mathrm{rpm}$ for $24 \mathrm{~h}$. After $24 \mathrm{~h}$, solutions were filtered to separate out activated carbon from each MB solution. Then, concentrations of each MB solution were analysed on a spectrophotometer (Shimadzu UV-2600) based on direct reading. The percentage removal of $100 \mathrm{mg} \mathrm{l}^{-1}$ each MB solution was calculated using Equation 1.

Equilibrium time of adsorption can be investigated by performing the effect of contact time on $\mathrm{MB}$ solution that has been removed by the adsorbent. Approximately $5.00 \mathrm{~g}$ of the adsorbent was added into $100 \mathrm{ml}$ of $100 \mathrm{mg}^{-1} \mathrm{MB}$ dye and was shaken at $100 \mathrm{rpm}$ at several time intervals which were $3 \mathrm{~h}, 6 \mathrm{~h}, 12 \mathrm{~h}$ and $24 \mathrm{~h}$. The concentration of the MB solution was recorded at each time interval using direct reading spectrophotometer (Shimadzu UV-2600).

The kinetic model can be investigated through the effect of contact time on MB solution that has been removed by the adsorbent. Approximately $5.00 \mathrm{~g}$ of the adsorbent was added into $100 \mathrm{ml}$ of $100 \mathrm{mg}^{-1} \mathrm{MB}$ dye and was shaken at $100 \mathrm{rpm}$ at several time scales which were $1 \mathrm{~min}, 5 \mathrm{~min}, 10 \mathrm{~min}, 20 \mathrm{~min}, 30 \mathrm{~min}, 40 \mathrm{~min}$, $50 \mathrm{~min}$ and $60 \mathrm{~min}$. The concentration of the MB solution was monitored at specific time durations using direct reading spectrophotometer (Shimadzu UV-2600). 


\section{RESULTS AND DISCUSSION}

\subsection{Characterisation of RSSAC}

\subsubsection{FTIR analysis}

FTIR spectra were acquired for the purpose of characterising the surface of RSSAC. Various functional groups present on the surface of RSSAC are responsible for favourable uptake of numerous types of molecular species. Thus, the chemical reactivity of functional groups plays a pertinent role in the adsorption of MB dye. ${ }^{11}$ FTIR spectrum of RSSAC before adsorption is shown in Figure 1 where it illustrates the presence of main functional groups, which are hydroxyl groups, carboxyl groups and carbonyl groups on the surface of RSSAC. IR peak positioned at $3412 \mathrm{~cm}^{-1}$ corresponds to $\mathrm{O}-\mathrm{H}$ stretching vibration due to the intermolecular hydrogen bonding of alcohols, phenols and carboxylic acids. This verifies the presence of free hydroxyl groups on the adsorbent surface. ${ }^{11}$

Based on the spectrum, RSSAC also showed four other major peaks at $3065 \mathrm{~cm}^{-1}$, $1706 \mathrm{~cm}^{-1}, 1568 \mathrm{~cm}^{-1}$ and $1385 \mathrm{~cm}^{-1}$. The bands in the region of $3065-1385 \mathrm{~cm}^{-1}$ were assigned to the stretching of $=\mathrm{C}-\mathrm{H}$ of aromatic and asymmetric aliphatic alkyl groups such as $-\mathrm{CH}_{2}$ and $-\mathrm{CH}_{3}$, respectively. Furthermore, a sharp peak at $1568 \mathrm{~cm}^{-1}$ corresponds to the $\mathrm{C}=\mathrm{C}$ stretching vibration of cyclic alkene generally found in carbonaceous materials such as activated carbon. ${ }^{11}$

FTIR spectrum of RSSAC after the adsorption process was also acquired to prove the presence of MB dye on the surface of the adsorbent as shown in Figure 1. Based on Figure 1, additional peaks appeared at $1725 \mathrm{~cm}^{-1}, 1367 \mathrm{~cm}^{-1}, 1253 \mathrm{~cm}^{-1}$ and $782 \mathrm{~cm}^{-1}$ upon the adsorption of MB dye onto RSSAC. The peaks at $1725 \mathrm{~cm}^{-1}$, $782 \mathrm{~cm}^{-1}$ and $1367 \mathrm{~cm}^{-1}$ were due to the presence of $\mathrm{C}=\mathrm{O}, \mathrm{C}-\mathrm{S}$ and nitro compound (N-O), respectively. Next, the broad peak positioned at $1253 \mathrm{~cm}^{-1}$ corresponds to the existence of amine compound, C-N. ${ }^{18}$ 


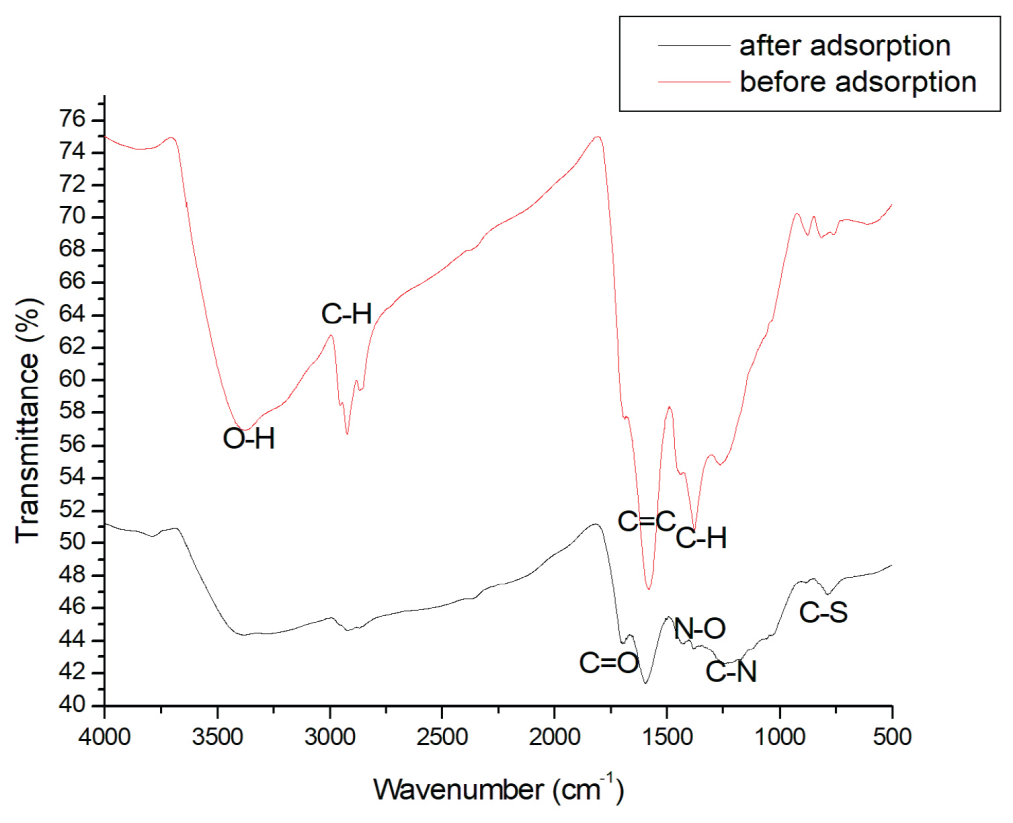

Figure 1: FTIR spectra RSSAC before and after adsorption.

\subsubsection{BET analysis}

BET analysis for RSSAC was conducted to determine the most suitable adsorption isotherm type based on IUPAC classification. ${ }^{6}$ Table 1 shows the surface area, pore volume and pore diameter of RSSAC, which are $2.15 \mathrm{~m}^{2} \mathrm{~g}^{-1}$, $0.0018 \mathrm{~cm}^{3} \mathrm{~g}^{-1}$ and $3.36 \mathrm{~nm}$, respectively. In view of the $\mathrm{N}_{2}$ adsorption-desorption isotherm (Figure 2), the shape of the hysteresis loop indicated the presence of a mesoporous surface structure of RSSAC, corresponding to Type IV adsorption isotherm, which is often correlated to the presence of slit-shaped mesopores. ${ }^{19}$ Obtaining a low BET surface area for RSSAC was due to the potassium compound covering the surface of activated carbon. ${ }^{20}$ However, SEM image showed the existence of high amount of pores on the surface of the adsorbent, indicating that the interference of potassium compound was moderately significant.

Table 1: BET summary for RSSAC.

\begin{tabular}{ll}
\hline Adsorbents & RSSAC \\
\hline Surface area $\left(\mathrm{m}^{2} \mathrm{~g}^{-1}\right)$ & 2.15 \\
Pore volume $\left(\mathrm{cm}^{3} \mathrm{~g}^{-1}\right)$ & 0.0018 \\
Pore diameter $(\mathrm{nm})$ & 3.36 \\
\hline
\end{tabular}


In addition, the pore size distribution of RSSAC (Figure 2) confirmed the actual pore structure of RSSAC. Activating temperature is an important parameter which can affect the pore structure of produced activated carbon, which revealed that the reaction rate between activating agent and carbon increased geometrically as the temperature rate increased. ${ }^{19}$ In the present work, $400^{\circ} \mathrm{C}$ was used as the carbonisation temperature to produce mesoporous activated carbon.

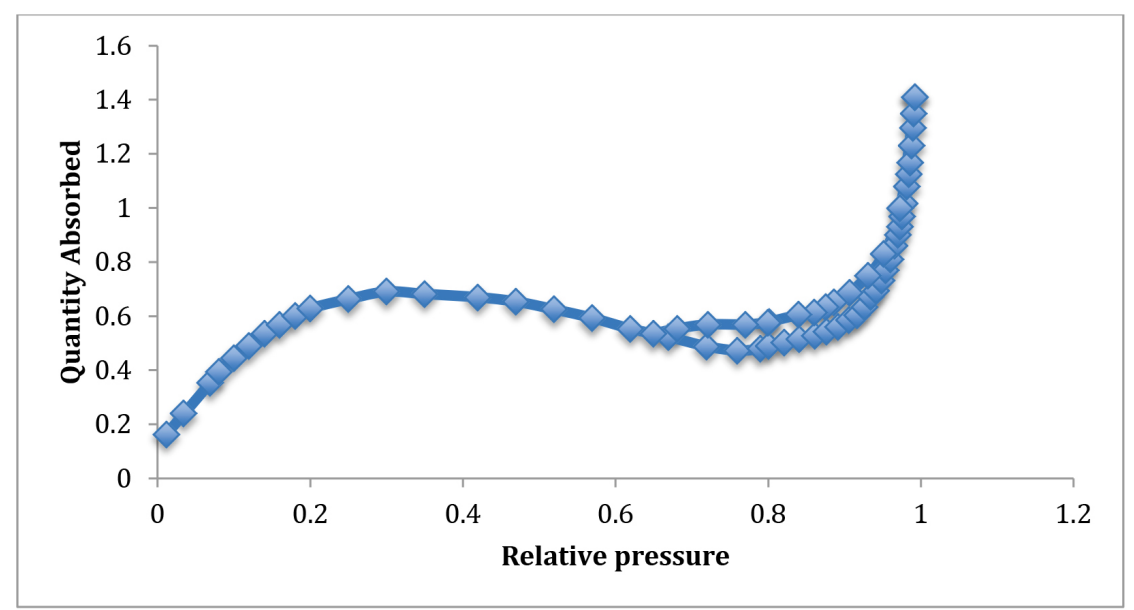

(a)

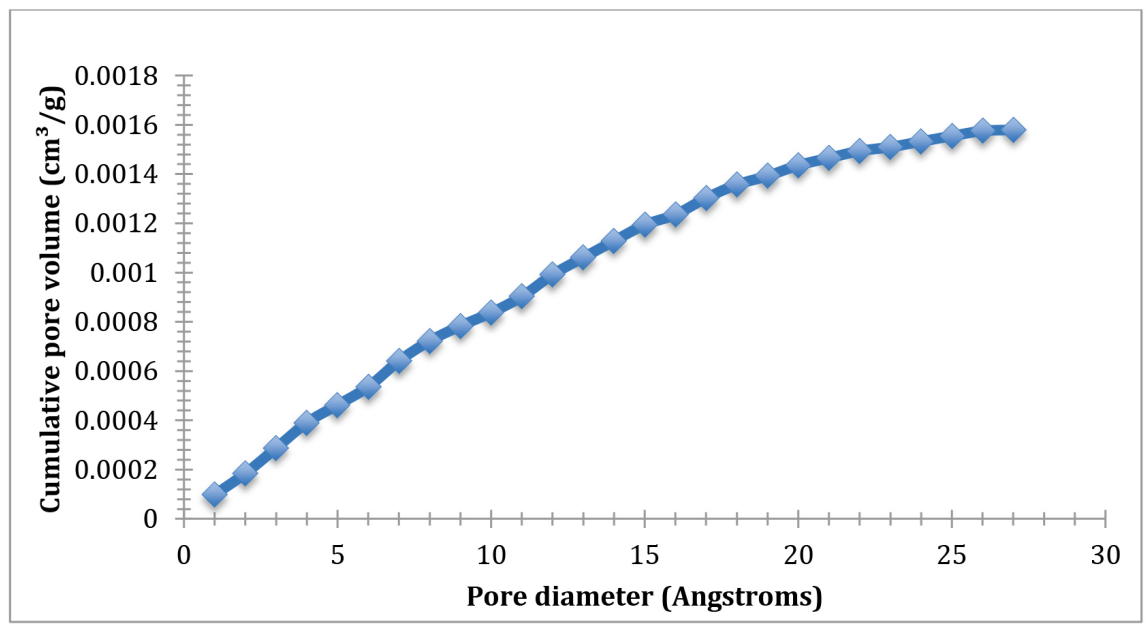

(b)

Figure 2: Illustrations of (a) $\mathrm{N}_{2}$ adsorption isotherm plot for RSSAC, and (b) pore size distribution for RSSAC. 


\subsubsection{SEM and EDX analyses}

The morphological structure of RSSAC was studied using SEM analysis. EDX analysis displays the major elements present in the adsorbent material. The morphological structure of RSSAC is shown in Figure 3. Based on the SEM image obtained at 3000X magnification, RSSAC showed the existence of pores with large pore diameter equivalent to the pore diameter obtained from BET analysis. The elemental analysis of RSSAC is tabulated in Table 2. According to Table 2, $\mathrm{C}$ and $\mathrm{K}$ percentage of RSSAC was recorded at $99.73 \%$ and $0.27 \%$, respectively. Acquiring almost close to $100 \%$ of $\mathrm{C}$ proved that RSSAC was pure with the presence of minute amount of impurities or foreign species.

Table 2: EDX elemental analyses for RSSAC.

\begin{tabular}{ll}
\hline Elemental & Weight $(\%)$ \\
\hline $\mathrm{C}$ & 99.73 \\
$\mathrm{~K}$ & 0.27 \\
\hline Totals & 100.00 \\
\hline
\end{tabular}

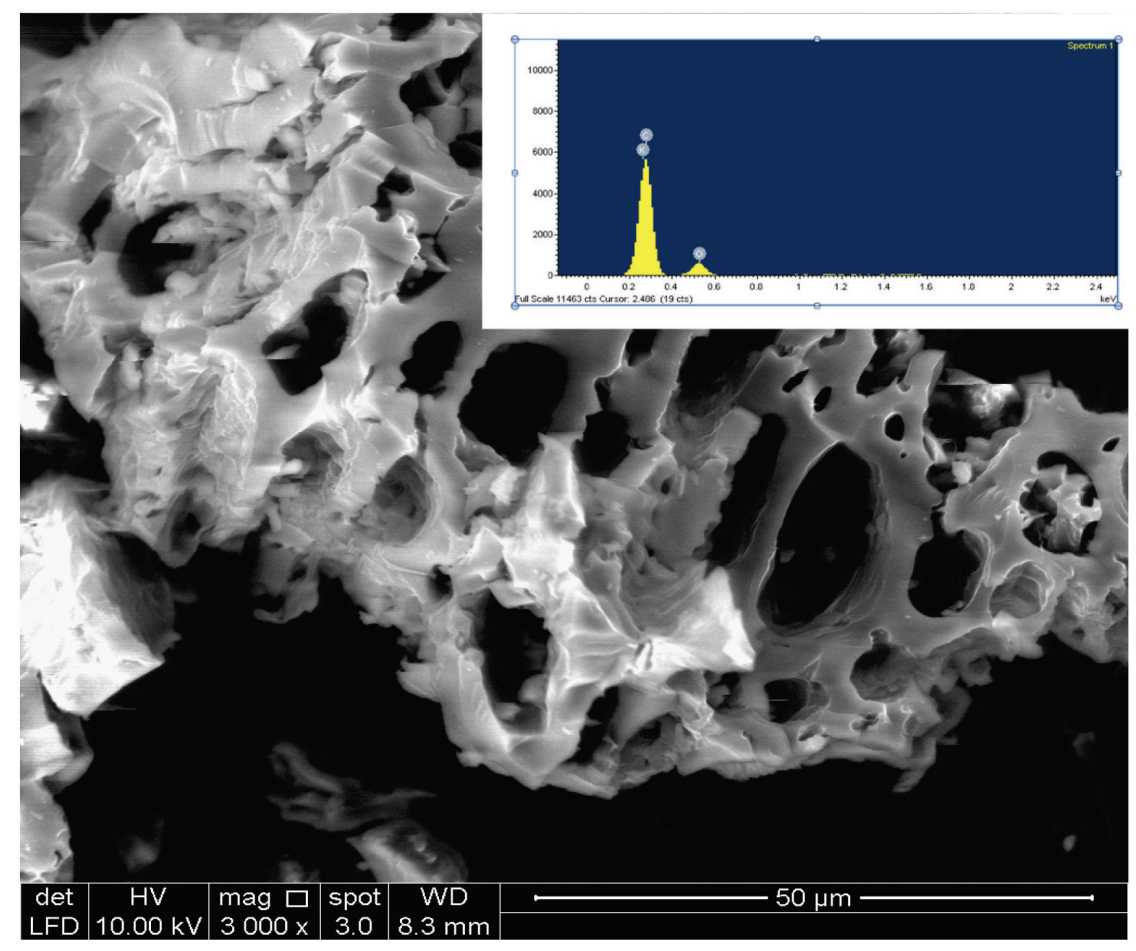

Figure 3: SEM and EDX image of the RSSAC (3000X magnification). 


\subsubsection{TGA analysis}

The rate of weight loss of activated carbon as a function of temperature was studied to investigate the thermal behaviour of RSSAC. Derivative thermal gravimetric (DTG) and thermal gravimetric (TG) curves of RSSAC are shown in Figure 4.

According to the DTG peaks, the thermal decomposition of RSSAC took place in two well-evidenced stages with significant mass losses. The initial mass loss of RSSAC due to moisture loss occurred in the range of $29^{\circ} \mathrm{C}-144^{\circ} \mathrm{C}$ with a percentage loss of $4.59 \%$. The second stage of mass loss occurred commencing from $119^{\circ} \mathrm{C}$ to $914^{\circ} \mathrm{C}$ with a percentage loss of $37.15 \%$ due to the existence of volatile compounds. RSSAC's total mass loss was recorded at $41.65 \%$. Therefore, RSSAC can be considered as a thermally stable activated carbon at high temperatures.

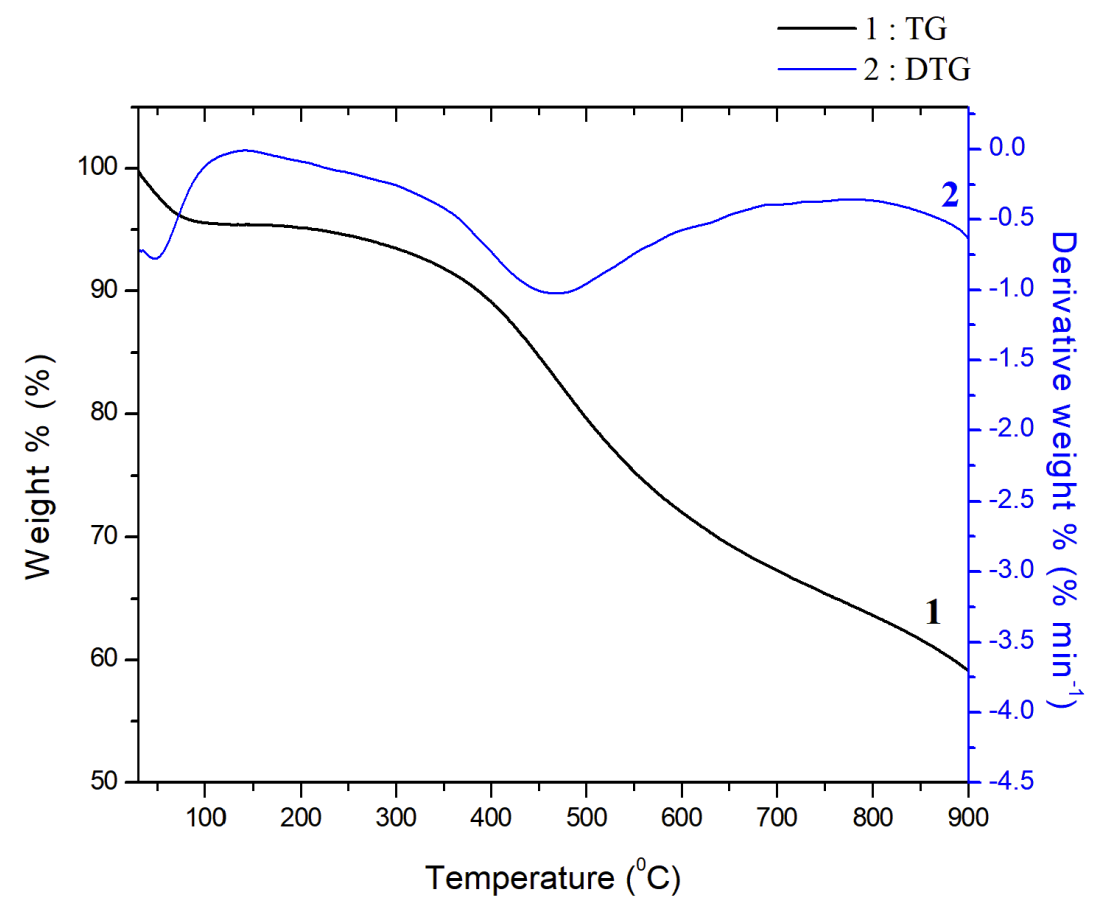

Figure 4: TG and DTG curves for RSSAC.

The initial stage of mass loss was due to the release of adsorbed water. The slow thermal decomposition of organic carbon structures of hemicellulose, cellulose or lignin occurred at the second stage of mass loss in a wider temperature range of $119^{\circ} \mathrm{C}-600^{\circ} \mathrm{C} .{ }^{11}$ Based on the TG curves, RSSAC showed a drastic mass loss 
above $500^{\circ} \mathrm{C}$, which corresponds to the decomposition of functional groups and partial gasification of least thermally stable fragments of the carbon structure. ${ }^{21}$

\subsection{Batch Adsorption Studies}

\subsubsection{Effect of adsorbent dosage}

The percentage removal and adsorption capacity of MB by RSSAC is shown in Figure 5. The dosages of RSSAC varied from $0.01 \mathrm{~g}$ to $10.0 \mathrm{~g}$ of activated carbon in batch adsorption at a constant $\mathrm{pH}$ of 6.0 , shaken at $100 \mathrm{rpm}$ for $24 \mathrm{~h}$. MB dye concentration was fixed at $100 \mathrm{ppm}$. Based on Figure 5, the adsorbents displayed an increase in the percentage of removal but showed a decrease in adsorption equilibrium when the dosage of adsorbent was increased. The increase in percentage of removal as the dosage of adsorbent was increased was a result of from the increase of adsorbent's active sites for the adsorption of MB dye molecules and greater availability of surface area to volume ratio of the adsorbent. ${ }^{22}$

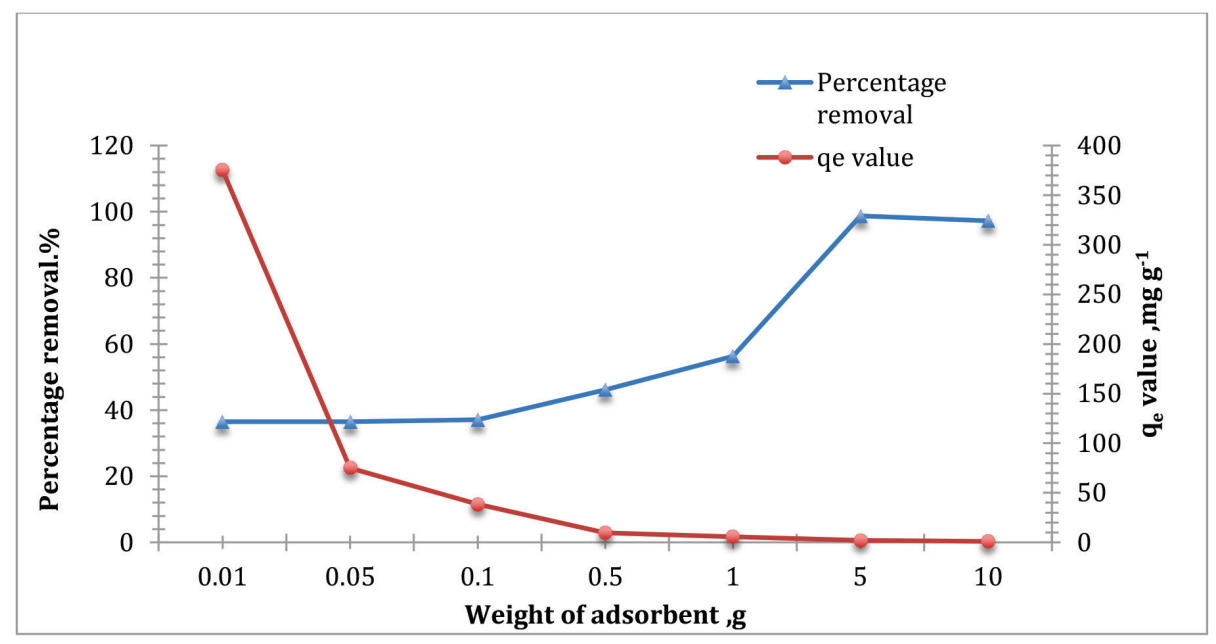

Figure 5: Effect of dosage of adsorbent on the removal of MB dye by RSSAC and $\mathrm{q}_{\mathrm{e}}$ value (conducted at room temperature, shaken at $100 \mathrm{rpm}$ for $24 \mathrm{~h}$ ).

RSSAC achieved the highest percentage of removal of $98.71 \%$ at $5.0 \mathrm{~g}$ dosage. Therefore, the optimum dosage of RSSAC was determined as $5.0 \mathrm{~g}$ per $100 \mathrm{ml}$. It was noted that the adsorption capacity, $\mathrm{q}_{\mathrm{e}}$ was inversely proportional to the dosage of the adsorbent. The higher the dosage, the lower the adsorption capacity was. This prominently revealed that the mass transportation of MB dye was not completely affected by the amount of adsorbent available, rather the difficulty in mass transfer should certainly be considered. Since the difficulty in mass transfer increased as the 
dosage of adsorbent increased, it resulted in a reduction in adsorption capacity. ${ }^{17} \mathrm{In}$ addition, the availability of high numbers of unsaturated sites of the adsorbent due to the increment in dosage resulted in low MB absorption.

\subsubsection{Effect of $\mathrm{pH}_{\mathrm{pzc}}$ and $\mathrm{pH}$ of $\mathrm{MB}$ dye}

Figure 6 shows the graph on the effect of $\mathrm{pH}_{\mathrm{pzc}}$ and $\mathrm{pH}$ of $\mathrm{MB}$ dye. $\mathrm{pH}_{\mathrm{pzc}}$ is one of the most important aspects required in studying the effect of $\mathrm{pH}$ of the solution on the adsorption characteristics of the adsorbent surface since it gives information on $\mathrm{pH}$ where adsorbent's net surface charge becomes zero. ${ }^{17}$ The intersection point between two lines as shown in Figure 6 is known as the end point of $\mathrm{pH}_{\mathrm{pzc}}$ where the value was $\mathrm{pH} 7.9$ for RSSAC. At this point, the functional groups on acid and base no longer contribute to the $\mathrm{pH}$ of the solution. Meanwhile, the surface of RSSAC is positively charged at $\mathrm{pH} 7.9$ and below. Beyond the $\mathrm{pH}_{\mathrm{pzc}}$ point, the surface of RSSAC becomes negatively charged which allows it to easily adsorb cations in the base medium due to the presence of $\mathrm{OH}^{-}$and $\mathrm{COO}^{-}$species, which favour cations present in the cationic dye. ${ }^{23}$

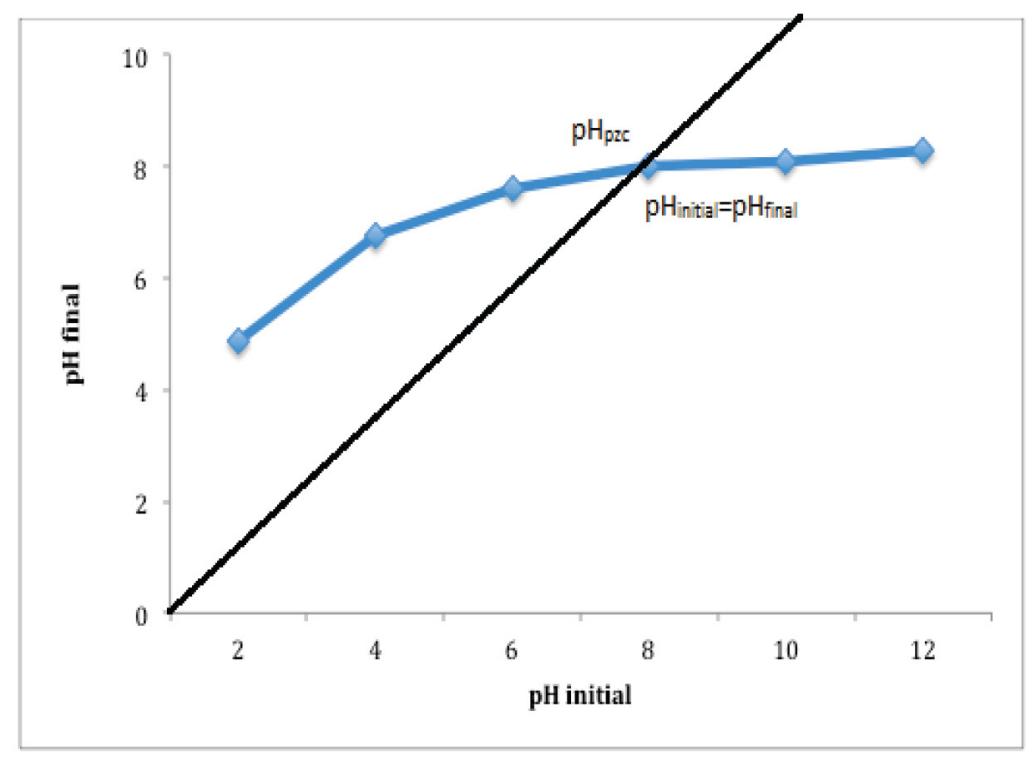

Figure 6: $\mathrm{pH}_{\mathrm{pzc}}$ curve of RSSAC (conducted at room temperature, shaken at $100 \mathrm{rpm}$ for $48 \mathrm{~h})$.

$\mathrm{pH}$ of MB dye is a circumstantial influencing factor for the adsorption of MB to occur at a maximum rate onto adsorbent surface. Figure 7 shows that the highest percentage removal of MB dye by RSSAC was observed at $\mathrm{pH}$ 6.0. The lowest 
percentage removal $\mathrm{MB}$ was observed at $\mathrm{pH}$ 4.0. This is due to the basicity of MB dye, releasing positively charged ions when dissolved in water. Thus, in acidic solution, $\mathrm{OH}^{-}$ions present on the surface of the adsorbent is favourable to the adsorption of cationic MB dye. ${ }^{24}$ According to Figure 7, the percentage removal of $\mathrm{MB}$ dye began to increase at $\mathrm{pH} 6.0$ and above. This is due to the fact that an increment in the $\mathrm{pH}$ of $\mathrm{MB}$ dye results in an increase of cationic charge, which is strongly favourable to get attached onto the negatively charged ions on the adsorbent. The increased adsorption of MB dye is due to an increase in the electrostatic attraction between positively charged MB dye and negatively charged ions on the adsorbent surface. ${ }^{2}$

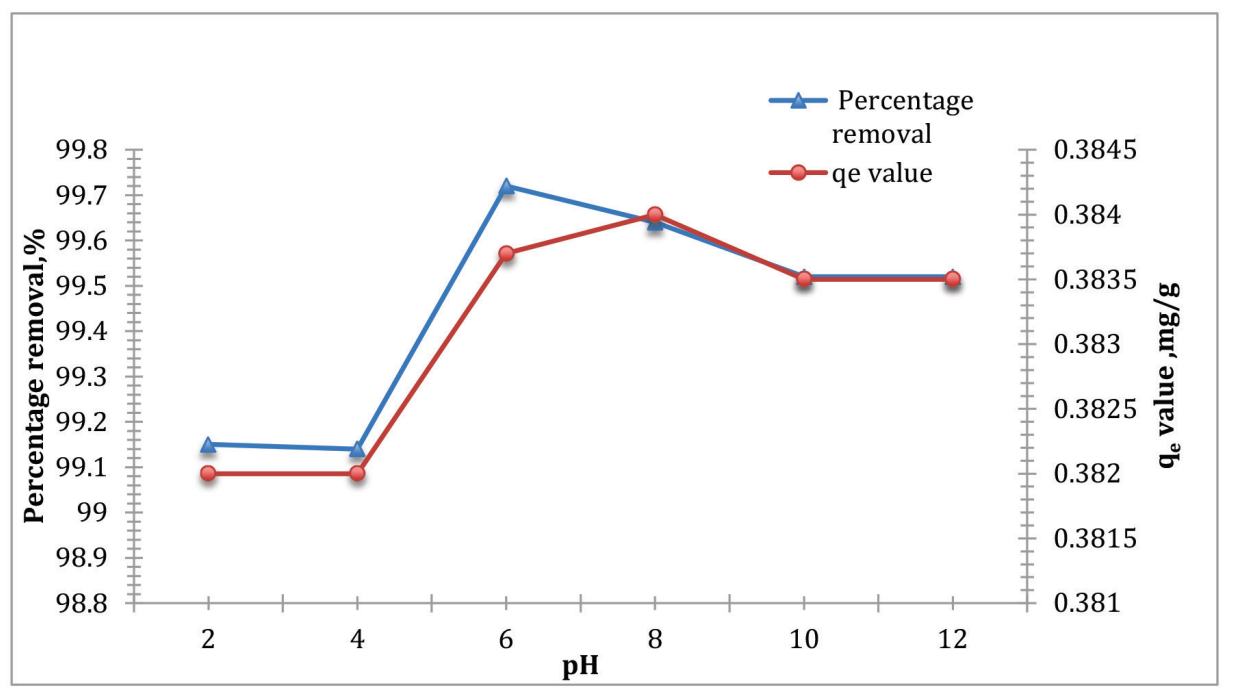

Figure 7: Effect of the varying $\mathrm{pH}$ on the removal of MB dye by RSSAC and $\mathrm{q}_{\mathrm{e}}$ value (conducted at room temperature, shaken at $100 \mathrm{rpm}$ for $24 \mathrm{~h}$ ).

Despite the increase and decrease in percentage of removal characteristics of MB dye by RSSAC at varying $\mathrm{pH}$ readings, the average percentage of removal of MB dye by RSSAC obtained was $99 \%$ in both acidic and basic media. It is evident that RSSAC is capable of exhibiting effective adsorption behaviour in both acidic and basic media in contrast to previous studies using Ficus carica bast as an activated carbon adsorbent for the removal of MB dye, obtaining just $90 \%$ of removal even at $\mathrm{pH} 10.0$ and above. ${ }^{18}$

\subsubsection{Effect of contact time}

The minimum period required to achieve equilibrium within the adsorption system can be obtained through an analysis of contact time between the adsorbent and MB 
dye. ${ }^{25}$ The relationship between contact time and the percentage removal of $\mathrm{MB}$ dye by RSSAC is shown in Figure 8. Based on Figure 8, the highest percentage removal of $\mathrm{MB}$ dye was observed at $1 \mathrm{~h}$ for RSSAC with a percentage removal of $99.62 \%$. The result proved that RSSAC exhibited fast and efficient adsorption performance since it was able to remove up to $99 \%$ of MB dye within the first hour of contact time. Figure 8 shows varying characteristics of percentage removal as it starts to decrease from $99 \%$ at $1 \mathrm{~h}$ to $97 \%$ at $6 \mathrm{~h}$ and then the percentage removal slightly increased to $98 \%$. This showed that the adsorbent already achieved the optimum time to adsorb MB dye and the reason could be due to the decrease of available active sites of the adsorbent for further uptake after equilibrium condition has been established..$^{18,22}$ Hence, it can be concluded that fast and effective removal of solution contaminants is highly important and becomes a desirable aspect of the adsorbent.

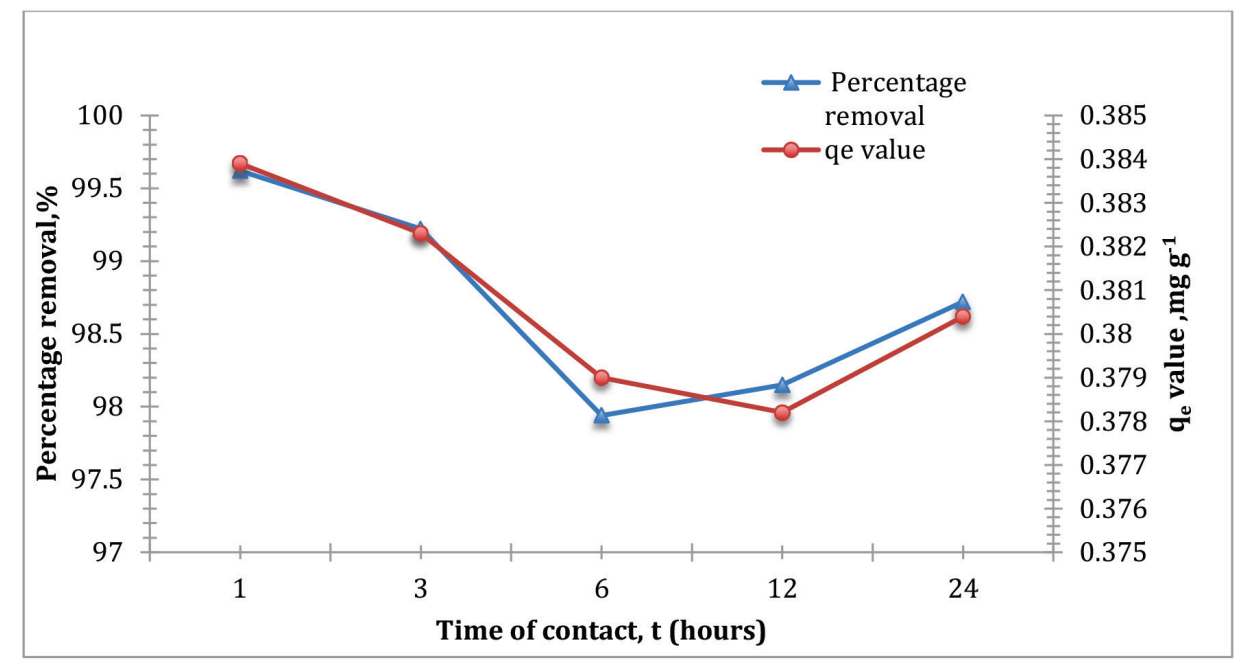

Figure 8: Effect of the contact time on the removal of MB dye by RSSAC and $\mathrm{q}_{\mathrm{e}}$ value (conducted at room temperature, shaken at $100 \mathrm{rpm}$ for $24 \mathrm{~h}$ ).

\subsubsection{Kinetic studies}

Previous studies on contact time between adsorbents and adsorbates explain the mechanisms that control the adsorption process and are determined by pseudofirst and pseudo-second-order kinetic models. ${ }^{17}$ Equation 3 depicts the pseudo-first order equation:

$$
\log \left(\mathrm{q}_{\mathrm{e}}-\mathrm{q}_{\mathrm{t}}\right)=\log \mathrm{q}_{\mathrm{e}}-\frac{\mathrm{k}_{1}}{2.303} \mathrm{t}
$$


where $\mathrm{k}_{1}\left(\mathrm{~min}^{-1}\right)$ is the rate constant and $\mathrm{q}_{\mathrm{e}}$ and $\mathrm{q}_{\mathrm{t}}$ refer to the amount of sorption at equilibrium $\left(\mathrm{mg} \mathrm{g}^{-1}\right)$ and at time $\mathrm{t}(\mathrm{min})$, respectively.

The sorption rate at constant value, $\mathrm{k}_{1}$ and adsorption amount of $\mathrm{q}_{\mathrm{e}, \mathrm{cal}}$ can be calculated by plotting $\log \left(q_{e}-q_{t}\right)$ against time, $t$ as shown in Figure 9(a). Table 3 illustrates the rate constant and $\mathrm{R}^{2}$ for pseudo-first-order kinetic model representing values of $0.1485 \mathrm{~min}^{-1}$ and $0.7656 \mathrm{~min}^{-1}$, respectively. It was revealed that there was a relative deviation between the calculated and the experimental $\mathrm{q}_{\mathrm{e}}$ values where $\mathrm{q}_{\mathrm{e}, \text { cal }}$ obtained for pseudo-first-order kinetic model was $0.0378 \mathrm{mg} \mathrm{g}^{-1}$ which was slightly lower than the experimental value, $\mathrm{q}_{\mathrm{e}, \mathrm{exp}}$. Therefore, the adsorption kinetics were better explained based on pseudo-second-order kinetic model using Equation 4 as mentioned below:

$$
\frac{\mathrm{t}}{\mathrm{q}_{\mathrm{t}}}=\frac{1}{\mathrm{k}_{2} \mathrm{qe}^{2}}+\frac{1}{\mathrm{q}_{\mathrm{e}}} \mathrm{t}
$$

where $\mathrm{k}_{2}\left(\mathrm{~g} \mathrm{mg}^{-1} \mathrm{~min}^{-1}\right)$ was at a constant rate and $\mathrm{q}_{\mathrm{e}}$ and $\mathrm{q}_{\mathrm{t}}$ were in reference to the amount of dye adsorbed $\left(\mathrm{mg} \mathrm{g}^{-1}\right)$ at equilibrium and at any time $\mathrm{t}(\mathrm{min})$, respectively.

Table 3: Pseudo-first-order and pseudo-second-order rate constants, $\mathrm{q}_{\mathrm{e}, \text { cal }}$ and $\mathrm{R}^{2}$ at 100 ppm of MB dye adsorption onto RSSAC.

\begin{tabular}{lccccccc}
\hline & & \multicolumn{3}{c}{$\begin{array}{l}\text { Pseudo-first-order kinetic } \\
\text { model }\end{array}$} & \multicolumn{3}{l}{$\begin{array}{l}\text { Pseudo-second-order kinetic } \\
\text { model }\end{array}$} \\
\cline { 3 - 8 } $\begin{array}{l}\text { Concentration } \\
\text { initial, } \mathrm{C}_{\mathrm{o}}(\mathrm{ppm})\end{array}$ & $\begin{array}{c}\mathrm{q}_{\mathrm{e}, \text { exp }} \\
\left(\mathrm{mg} \mathrm{g}^{-1}\right)\end{array}$ & $\begin{array}{c}\mathrm{q}_{\mathrm{e}, \mathrm{cal}} \\
\left(\mathrm{mg} \mathrm{g}^{-1}\right)\end{array}$ & $\begin{array}{c}\mathrm{k}_{1} \\
\left(\mathrm{~min}^{-1}\right)\end{array}$ & $\mathrm{R}^{2}$ & $\begin{array}{c}\mathrm{q}_{\mathrm{e}, \text { cal }} \\
\left(\mathrm{mg} \mathrm{g}^{-1}\right)\end{array}$ & $\begin{array}{c}\mathrm{k}_{2} \\
\left(\mathrm{~g} \mathrm{mg} \mathrm{m}^{-1} \mathrm{~min}^{-1}\right)\end{array}$ & $\mathrm{R}^{2}$ \\
\hline 100 & 0.38 & 0.038 & 0.15 & 0.77 & 0.38 & 40.74 & 1 \\
\hline
\end{tabular}

A graph of $t / q_{t}$ against $t$ was plotted as shown in Figure 9(b) to infer the values of $\mathrm{k}_{2}$ and $\mathrm{q}_{\mathrm{e}, \text { cal }}$ through the intercept and slope of the graph. Based on Table 3, values of $\mathrm{R}^{2}$ and $\mathrm{q}_{\mathrm{e}, \text { cal }}$ obtained were $1 \mathrm{~g} \mathrm{mg}^{-1} \mathrm{~min}^{-1}$ and $0.3843 \mathrm{~g} \mathrm{mg}^{-1} \mathrm{~min}^{-1}$ respectively making evident that pseudo-second-order model has the best correlation among the kinetic models for RSSAC. Moreover, there was a strong relationship between the calculated $\mathrm{q}_{\mathrm{e}}\left(\mathrm{q}_{\mathrm{e}, \text { cal }}\right)$ and experimental $\mathrm{q}_{\mathrm{e}}\left(\mathrm{q}_{\mathrm{e}, \text { exp }}\right)$, where the value of $\mathrm{q}_{\mathrm{e}, \text { cal }}$ was closer to $\mathrm{q}_{\mathrm{e}, \mathrm{exp}}$. Since the adsorption process follows pseudo-second-order kinetics, it can be concluded that the adsorption process between the active sites of RSSAC and MB dye occurred through chemical adsorption and it was confirmed that the ratelimiting step is chemisorption, involving valence forces by sharing or exchanging of electrons. ${ }^{26,27}$ 
Pseudo-1st order

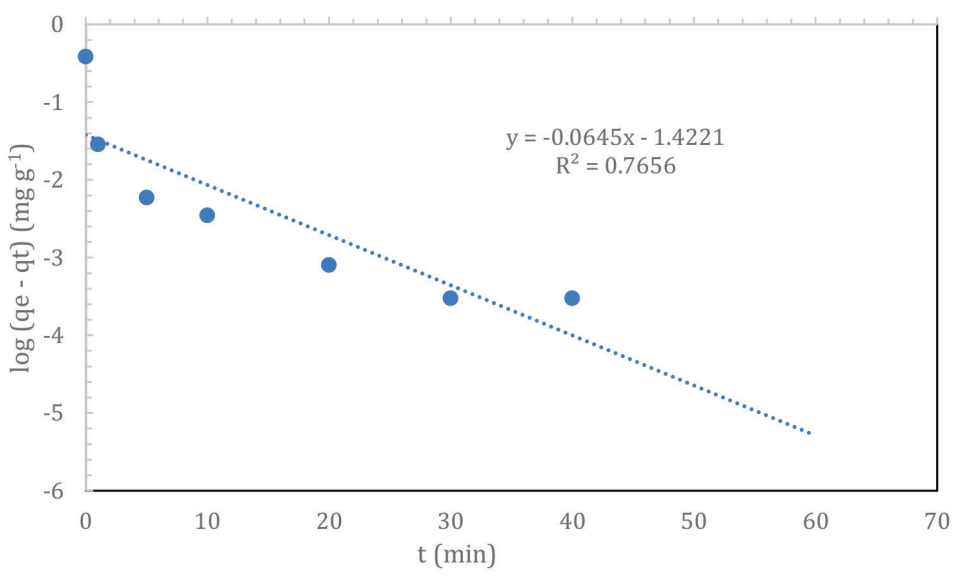

(a)

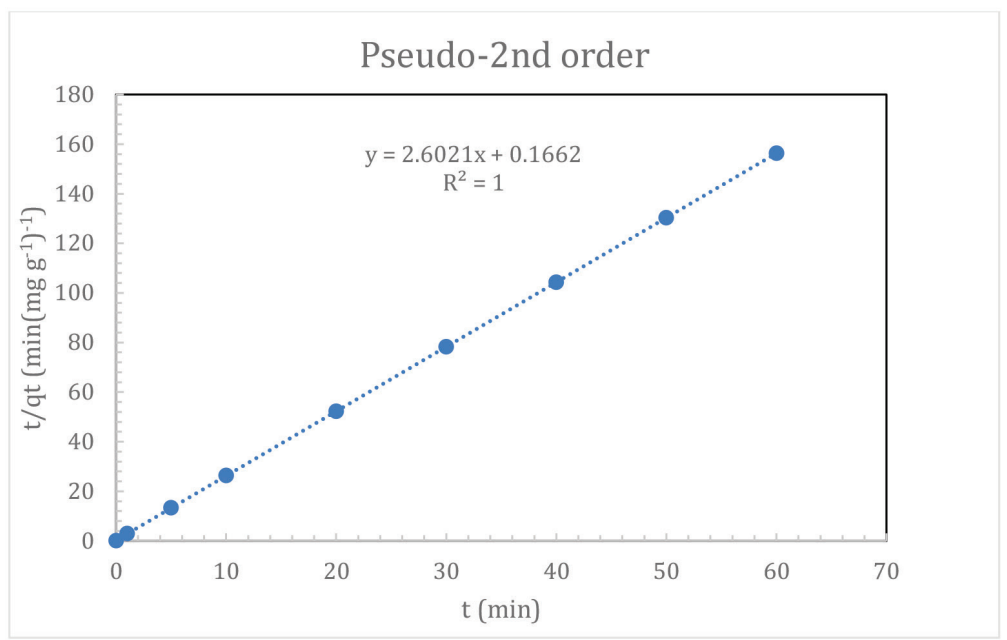

(b)

Figure 9: Kinetic studies for adsorption of MB dye onto RSSAC for (a) pseudo-firstorder, and (b) pseudo-second-order (conducted at room temperature, shaken at $100 \mathrm{rpm})$.

\section{CONCLUSION}

RSSAC showed promising adsorption performance in the removal of MB dye. Moreover, RSSAC has been proven to have rapid and efficient adsorption 
characteristics at short time intervals. RSSAC achieved a percentage removal $99 \%$ of $\mathrm{MB}$ dye within $1 \mathrm{~h}$. In view of $\mathrm{pH}$ dependent studies, RSSAC showed an excellent adsorption capacity in both acidic and basic media in the $\mathrm{pH}$ range of $\mathrm{pH}=2.0$ to $\mathrm{pH}=12.0$ with $99 \%$ removal. Additionally, the rate of adsorption was found to obey pseudo-second-order kinetic model. It can be concluded that RSSAC can perform as an alternative adsorbent for the removal of dyes in aqueous solutions with a high percentage removal of MB up to $99 \%$.

\section{ACKNOWLEDGEMENTS}

The authors would like to express their utmost gratitude to Universiti Sains Malaysia (USM) for conferment of the USM fellowship. Through this achievement, the authors are granted the opportunity to conduct this particular research. Additionally, the authors are immensely appreciative towards the university for aiding and providing financial support through the USM Bridging Grant (304/ PKMIA/6316041) and Research University Grant for Individual (RUI) Grant (1001/PKMIA/801107).

\section{REFERENCES}

1. Wen, Z. Q. et al. (2015). Co-deposition of catechol/polyethyleneimine on porous membrane for efficient decolorization of dye water. J. Matter. Chem. A, 3, 1443814444, https://doi.org/10.1039/C5TA02590G.

2. Aljeboree, A. M., Alshirifi, A. N. \& Alkaim, A. F. (2017). Kinetics and equilibrium study for the adsorption of textile dye on coconut shell activated carbon. Arab. J. Chem., 10, 3381-3393, https://doi.org/10.1016/j.arabjc.2014.01.020.

3. Güzel, F. et al. (2015). New low cost nanoporous carbonaceous adsorbent developed from carob (Ceratonia siliqua) processing industry waste for the adsorption of anionic textile dye: Characterization, equilibrium and kinetic modeling. J. Mol. Liq., 206, 244-255, https://doi.org/10.1016/j.molliq.2015.02.037.

4. Singh Rai, H. et al. (2005). Removal of dyes from effluent of textile and dyestuff manufacturing industry: A review of emerging techniques with reference to biological treatment. Cri. Rev. Env. Sci. Technol., 35, 219-238, https://doi. org/10.1080/10643380590917932.

5. De Gisi, S. et al. (2016). Characteristics and adsorption capacities of low-cost sorbent for wastewater treatment: A review. Sustain. Mat. Technol., 9, 10-40, https://doi.org/10.1016/j.susmat.2016.06.002.

6. Borhan, A. et al. (2016). Removal of $\mathrm{Cu}^{2+}$ and $\mathrm{Zn}^{2+}$ from single metal aqueous solution using rubber-seed shell based activated carbon. Proced. Eng., 148, 694701, https://doi.org/10.1016/j.proeng.2016.06.571. 
7. Cukierman, A. L. (2013). Review article: Development and environmental applications of activated carbon cloths. ISRN. Chem. Eng., 1-31, https://doi. org/10.1155/2013/261523.

8. Ghaedi, M. et al. (2015). Application of central composite for simultaneous removal of $\mathrm{MB}$ and $\mathrm{Pb}^{2+}$ ions by walnut wood activated carbon. Spectrochim. Acta $A, 135,479-499$, https://doi.org/10.1016/j.saa.2014.06.138.

9. Khandy, W. A. et al. (2017). Mesoporous zeolite-activated carbon composite from oil palm ash as an effective adsorbent for methylene blue. J. Taiwan Inst. Chem. Eng., 70, 32-41, https://doi.org/10.1016/j.jtice.2016.10.029.

10. Bhatnagar, A., Sillanpää, M. \& Witek-Krowrak, A. (2015). Agricultural waste peels as versatile biomass for water purification: A review. Chem. Eng. J., 207, 244-271, https://doi.org/10.1016/j.cej.2015.01.135.

11. Joshi, S. \& Pokharel, B. P. (2013). Preparation and characterization of activated carbon from Lapsi (Choerospondias axillaris) seed stone by chemical activation with potassium hydroxide. J. Inst. Eng., 9, 79-88, https://doi.org/10.3126/jie. v9i1.10673.

12. Borhan, A. \& Kamil, A. F. (2012). Preparation and characterization of activated carbon from rubber-seed-shell by chemical activation. J. Appl. Sci., 12, 1124-1129, https://doi.org/10.3923/jas.2012.1124.1129.

13. Sun, K. et al. (2006). Study on preparation of activated carbon from rubber seedshell with steam method. Chem. Ind. Prod., 26(2), 41-43.

14. Hameed, B. H. \& Daud, F. B. M. (2008). Adsorption studies of basic dye from agricultural waste: Havea brasiliensis seed coat. Chem. Eng. J., 139, 48-55, https://doi.org/10.1016/j.cej.2007.07.089.

15. Oladoja, N. A. et al. (2008). Removal of methylene blue from aqueous solution by rubber (Hevea brasiliensis) seed shell in a fixed-bed column. Asia-Pac. J. Chem. Eng., 3, 320-332, https://doi.org/10.1002/apj.134.

16. Berneth, H. (2008). Ullmann's encyclopedia of industrial chemistry. Weinheim, Germany: Wiley-VCH.

17. Tan, C. H. C., Sabar, S. \& Hussin, M. H. (2018). Development of immobilized microcrystalline cellulose as an effective adsorbent for methylene blue dye removal. S. Afr. J. Chem. Eng., 26, 11-24, https://doi.org/10.1016/j.sajce.2018.08.001.

18. Pathania, D., Sharma, S. \& Singh, P. (2017). Removal of MB by adsorption onto activated carbon developed from Ficus carica bast. Arab. J. Chem., 10, 14451451, https://doi.org/10.1016/j.arabjc.2013.04.021.

19. Sun, K. \& Jiang, J. C. (2010). Preparation and characterization of activated carbon from rubber-seed shell by pysical activation with steam. Biomass. Bioenerg., 34, 539-544, https://doi.org/10.1016/j.biombioe.2009.12.020.

20. Mopoung, S. et al. (2015). Characterization and properties of activated carbon prepared from Tamrind seeds by $\mathrm{KOH}$ activation for $\mathrm{Fe}(\mathrm{III})$ adsorption from aqueous solution. Sci. World J., Article ID 415961, https://doi. org/10.1155/2015/415961.

21. Bhattacharrrya, K. \& Sharma, A. (2005). Kinetics and thermodynamics of MB adsorption of Neem (Azadirachta indica) leaf powder. Dyes Pigm., 65, 51-59, https://doi.org/10.1016/j.dyepig.2004.06.016. 
22. Benard, E., Jimoh, A. \& Odigure, J. O. (2013). Heavy metals removal from industrial wastewater by activated carbon prepared from coconut shell. Res. J. Chem. Sci., 3, 3-9.

23. Pirbazari., A. E. et al. (2014). Alkali treated Foumanat tea waste as an efficient adsorbent for methylene blue adsorption from aqueous solution. Water. Resour. Ind., 6, 64-80, https://doi.org/10.1016/j.wri.2014.07.003.

24. Haitham, K., Razak, S. \& Nawi, M. A. (2014). Kinetics and isotherm studies of methyl orange adsorption by a highly recyclable immobilized polyaniline on a glass plate. Arab. J. Chem., https://doi.org/10.1016/j.arabjc.2014.10.010.

25. Nakce, H., Jr. et al. (2017). Removal of Cd (II) from water using the waste of jatropha fruit (Jatropha curcas L.). Appl. Water Sci., 7, 3207-3222..

26. Bazan, A. et al. (2016). Thermal analysis of activated carbon obtained from residue after supercritical extraction of hops. J. Therm. Anal. Calorim., 125, 1199-1204.

27. Feng, N. et al. (2011). Biosorption of heavy metals from aqueous solutions by chemically modified orange peel. J. Hazard. Mat., 185, 49-54, https://doi. org/10.1016/j.jhazmat.2010.08.114. 